\title{
Application of Configuration Software in Process Control Course Teaching
}

\author{
http://dx.doi.org/10.3991/ijet.v11i07.5845 \\ Chunguo Fei, Chunxin Li \\ Civil Aviation University Of China, Tianjin, China
}

\begin{abstract}
According to the characteristics of configuration software and process control courses, the configuration software is applied to teaching practical process control. Configuration software can realize the mathematical model design and the digital controller design for the controlled objects in the process control and can build different process control systems. As for the practical teaching process for process control, the combination of theory and simulation not only makes the boring process control theory more vivid, but also helps students to understand and remember the theoretical points easily and improves the students learning interests, efficiency and enthusiasm. Practical application prove that this method is an effective way to teach process control system. And it also provides a new idea for such kind of control courses.
\end{abstract}

Index Terms-Configuration software, KingView, Process control, Simulation teaching.

\section{INTRODUCTION}

Process control is an engineering discipline that deals with architectures, mechanisms and algorithms for maintaining the output of a specific process within a desired range. The process control system is widely used for production of mass processes such as paper manufacturing, power plants, chemicals, oil refining and other similar industries. Here the staffs in the central control room operate complex processes. So the process control is a practical course.

Process control, for education, which is one of the earliest development course of control theory in university, is an important branch of control technology. It involves various theories, technologies and methods in many fields, such as control theory, computer technology, information acquisition and process technology, automation instrumentation. And it is one of the most comprehensive courses for control specialty.

In the past, process control viewed temperature, pressure, flow, level, composition and other process parameters as controlled objects. With the rapid development of industry, controlled objects have been further extended to the entire process of industrial system, using statistical or engineering methods to deal with structure, mode of operation and the calculus in the process. Nowadays, process control has been developed into a discipline which is closely related to the process of industrial production. In the mean time, it becomes a highly technical and practical important discipline of automation specialty.

The aim of teaching process control course is to enable students to master methods and skills of analysis, design and operation of process control systems by applying the control theories to the production process, which lays a foundation for the further study and research of related fields in the future. Experimental teaching in the process control system is a vital part in this course[1]. Students can have a better understanding on the important concepts and methods by the experiments.

However, there are many negative factors affect students learning in the current teaching way. Traditional teaching focuses on theoretical study, which is difficult for students to understand. And experimental teaching is often seriously lagged behind the corresponding theoretical teaching. All of the conditions above make control process effects not ideal.

Based on the current situation of the teaching, this paper proposes a teaching method combining theory with simulation experiment in process control course. This paper clarifies a process control courseware applying configuration software in the process control teaching[2]. The courseware can establish virtual controlled objects in line with the relevant mathematical models of process control. At the same time, not only does it design process control algorithms by the DDC (Direct Digital Control) control method of computer control technology, but also it builds a control system[3]. The courseware makes the control system explanation more simple, easier for students to learn and understand[4]. In this process, students can have a full and comprehensive understanding on control algorithm by changing parameters and analyzing the response curve of the controlled object. In Summary, combination between theory and simulation experiments in process control course makes the theoretical knowledge more easily to understand and remember.

\section{The APPliCATION OF CONFIGURATION SOFtWARE IN PROCESS CONTROL COURSE}

Configuration software is specialized as a kind of software which is a collection of data acquisition and process control. During the teaching process, with configuration software, a simulation teaching is developed, and practical application has been shown in the classroom. The production technology, production process flow and the states of field devices have been visually demonstrated in this simulation for teaching process too.

This article will illustrate how to apply the configuration software to realize simulation teaching in process control course by showing some typical and very important theories and skills.

\section{A. The Dynamic Characteristics of the Controlled Object}

For a process control system, it is necessary to know the dynamic characteristics of the controlled object. Namely, the relationship between the input and the output of con- 
trol system component must be known[5]. Based on deeply understanding dynamic characteristics of controlled object, a reasonable dynamic performance index and the control system have been designed.

In the process control industry, tank is the most common controlled object. Therefore, the configuration software is applied to show the dynamic characteristics of the tanks as the first example in process control system. According to the mathematical model in [6], the water level control systems of the single tank and the double tank are established. For the single-tank control system, valve 1 opening is 30 , valve 2 opening is 6 , cross-section area of tank is 15 , water level height is 25 . For the double-tank control system, valve 1 opening is 30 , valve 2 opening is 15 , cross-section area of tank F1 is 100 , cross-section area of tank F2 is 15, water level height H1 is 100, water level height $\mathrm{H} 2$ is 40 . These parameters can be changed to implement different processes.

The dynamic characteristic of the controlled objects in the graph is consistent with the same situation in [6], especially the "S" curve presents the dynamic characteristics of the double-tank control system. Students can observe the different controlled object dynamic curve by double clicking on the white figure in the graph and resetting the new value, so as to further understand the relationship between the input and the output of controlled object and the dynamic characteristics of the tank.

\section{B. Simple Control Systems and PID Control System}

Simple control systems (single--loop control systems) are able to satisfy the plant requirements in most common circumstances. Therefore, the simple control systems are very common. It is very important to develop an understanding of simple control systems. A simple control system is shown in Figure 3. In this simple control system, the default is 50 , and the damping ratio of the control response curve is $4: 1$. Based on this system, students can understand the composition of the simple control system and the damping ratio of the control response curve.

PID (P-proportion, I-integration, D-differentiation) control is ubiquitous. Theoretically, it is simple to understand. However, design and implementation of PID controllers could be difficult and complex. PID controller relies only on the measured process variables, not on knowledge of the underlying process. In this case, a PID control system is built by applying the configuration software in Figure 4. The PID controller and controlled object are created to ActiveX control respectively by using VB6.0. PID controller ActiveX control can realize two different type discrete PID. One is position PID, the other is incremental PID. Two different type discrete PID can be chosen by clicking the corresponding option button. The PID can be arbitrarily set by inputting data into textbox. The sampling period can be set with the same method.

Controlled object ActiveX control is produced, according to second-order controlled object mathematical model with pure delay or not. Controlled object can be set as first-order or second-order with pure delay or not.

By setting parameters for these two ActiveX controls, a simple PID control system is built. This PID control system enables students to develop an understanding of PID process control. The P, I and D function can be known by setting different parameters and analyzing the simulation results. In the end, students can master skills for tuning PID.

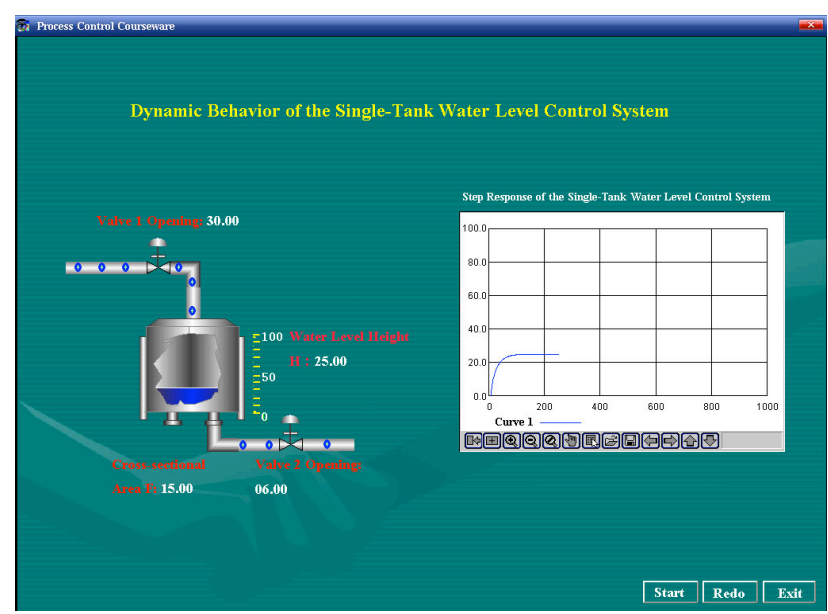

Figure 1. The Single-Tank Dynamic Characteristics

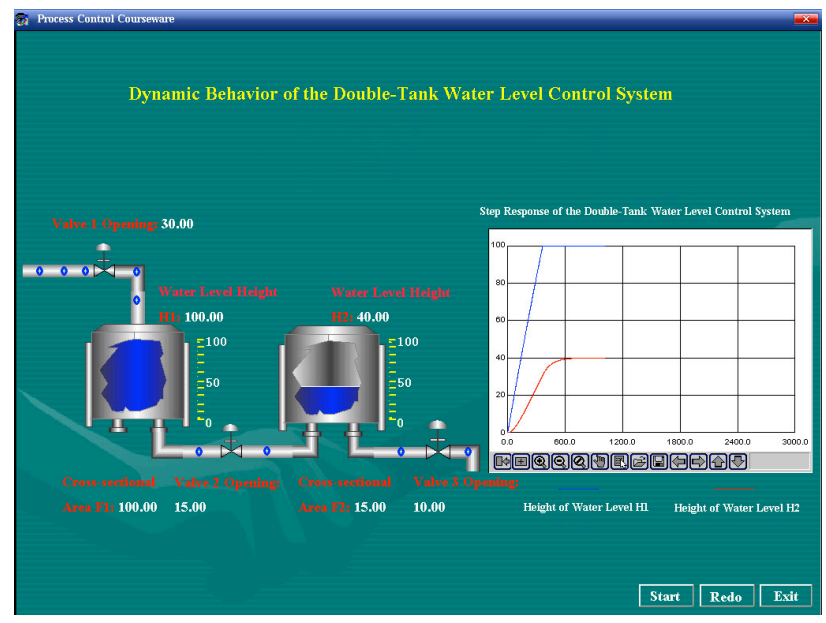

Figure 2. The Double-Tank Dynamic Characteristics

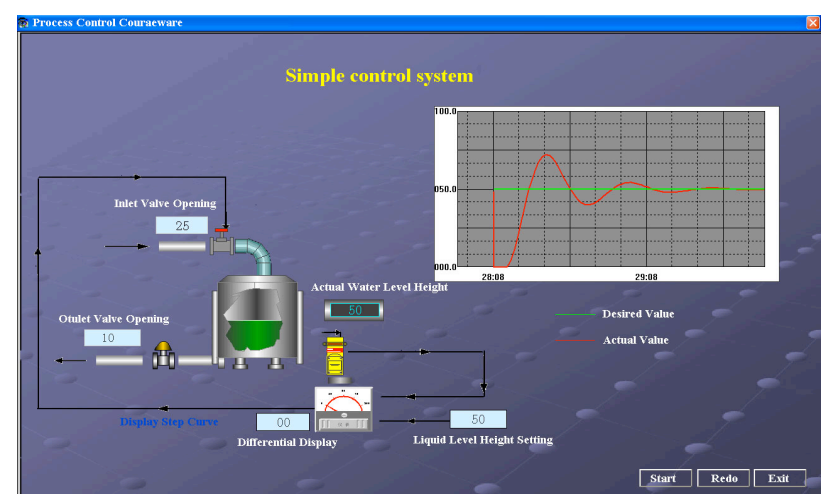

Figure 3. The Simple Control System

Figure 4 gives a simulation example. The controlled object can be presented as

$$
\frac{20}{1.6 s^{2}+4.4 s+1} \text {. }
$$

The position PID has been chosen. Here, $\mathrm{P}$ is 0.005 , I is 0.002 , D is 0.002 , and the sampling period is 60 millisecond. The figure shows the control result is very well. In Figure 4, the red curve and the blue one represents set point value and actual value, respectively. The blue curve will match the red curve without overshoot immediately. Based on the illustration above, the control process satisfies the requirements. The green curve is the control value. 


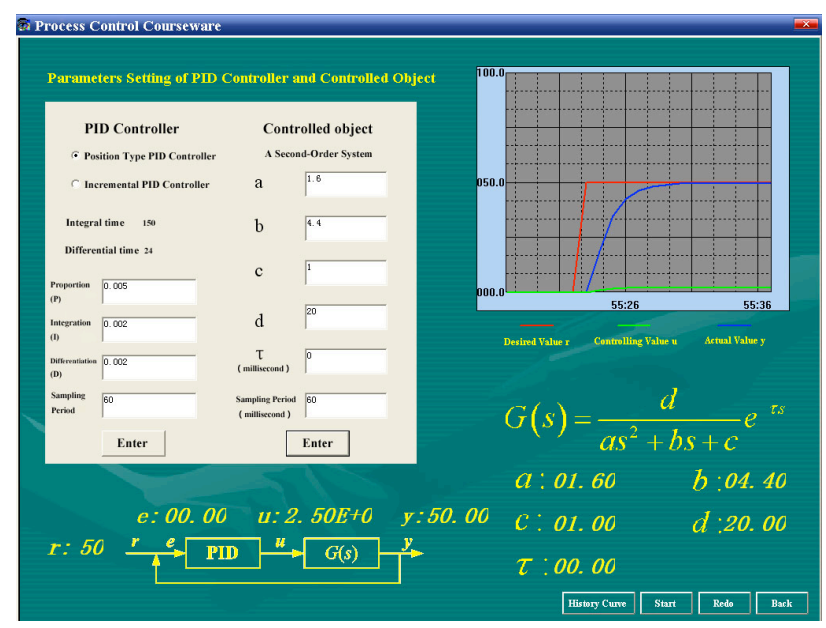

Figure 4. PID Controller and Controlled Object

\section{Ratio Control System and Cascade Control System}

The ratio control architecture is employed to maintain the flow rate of one stream in a process at a defined or specified proportion relative to that of another. A common application for ratio control is combining or blending two feed streams to produce a mixed flow with a desired composition or physical property.

Two process variables of the control system are kept at a fixed ratio, regardless of the variation of the variables, when flow rates in two separate fluid conduits are held at a fixed ratio.

Figure 5 shows the ratio control system. In this system, the SP is set to 30 ; the ratio is set to $2 . \mathrm{P}, \mathrm{I}, \mathrm{D}$ is set to 0.6 , $20,0.1$, respectively. At the last, the desired value and the actual value become one.

A cascade control system is a multiple-loop system where the primary variable is controlled by adjusting the set point of a related secondary variable controller. Therefore, the secondary variable affects the primary variable through the process.

Figure 6 shows the cascade control system. In the system, the SP is set to 80 ; the parameters of the auxiliary regulator are set as follows. $\mathrm{P}=0.25, \mathrm{I}=1000, \mathrm{D}=0.15$. The parameters of the main regulator are $0.26,20,0.1$ with the sequence P, I, D. The control effect will be changed with the different controller parameters.

By studying the system examples before, students not only understand the ratio control system and the cascade control system, but also have a good learning of parameters setting and controlling effect.

\section{Decoupling Control System}

Multi-input multi-output control systems occur very frequently in practice and bring difficult control problems for the operating personnel. In order to make each input only control one corresponding output, certain suitable control law is to eliminate the coupling between the control loops in the system.

Figure 7 shows the decoupling status of the decoupling control system. When $\mathrm{G}_{\mathrm{ij}}$ and $\mathrm{M}_{\mathrm{ci}}$ are set different values, a system has different coupling relationship between the two control loops. Click the "decoupled" button, the system is decoupled; click the "coupled" button, the system has a coupling relationship.

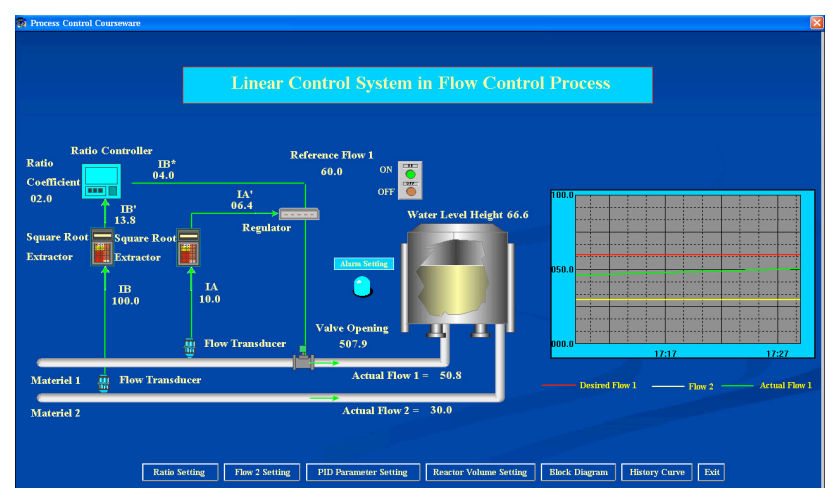

Figure 5. The Ratio Control System

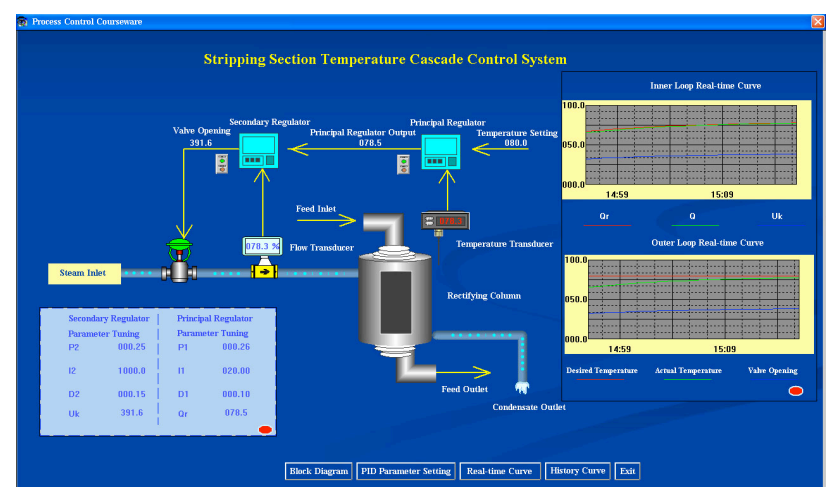

Figure 6. The Cascade Control System

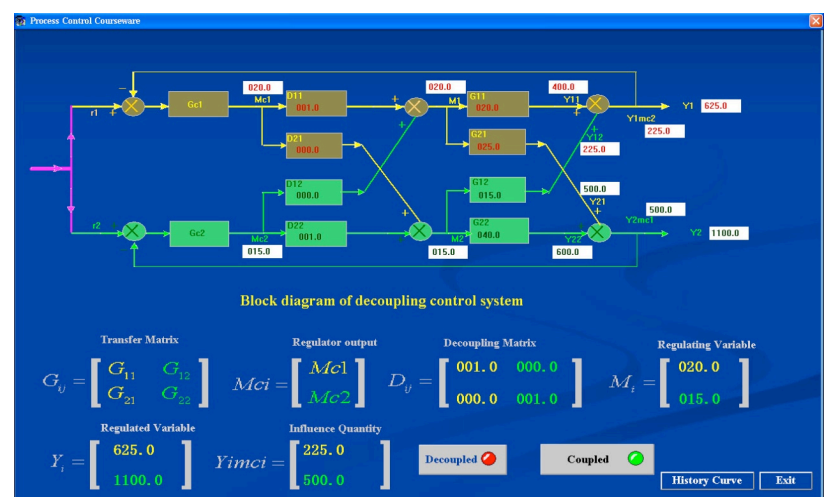

(a) The Decoupled State

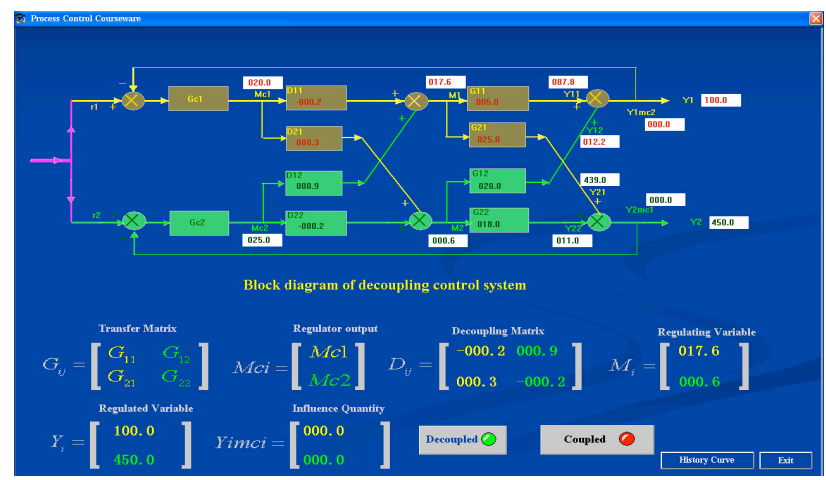

(b) The Coupled State

Figure 7. The decoupling Control System

This system can help students to understand the difference and characteristic of decouple and coupling, the reasons for coupling status becoming a decoupled status and the basic methods to decouple a system. 


\section{SHORT PAPER}

\section{ApPlication of CONFIGURATION SOFTWARE IN Process CONTROL COURSE TEACHING}

\section{CONCLUSION}

This paper presents a teaching method for process control course, by applying the configuration software to make a courseware. In the courseware, the values of controlled objects and control algorithms can be changed by entering corresponding parameters in the courseware to make simulation. During the teaching process, using the simulation experiment in the classroom, the theory and virtual practice are combined. It helps students to fully understand the theoretical knowledge and make the theory more vivid and understood more easily. At the same time, this configuration software has been used in process control course design. Students are required to design a simulation process control system by applying the KingView. The teaching method can also be applied to other control courses such as Principle of Automatic Control and Principle of Computer.

\section{REFERENCES}

[1] G. lu and Z. Huang, "Reform and practice of experimental teaching in process control course," Equipment Manufacturing Technology, vol. 3, pp. 171-172, 2013.

[2] Z. Guo and T. Zhang, "Research on teaching and practice method of process control course," China Education Innovation Herald, vol. 2, pp. 46-48, 2013.
[3] Q. Fang and Z. Luo, "Computer simulation experiment teaching of process control system," Journal of Electrical \& Electronic Engineering Education, vol. 28, pp. 54-55, 2006.

[4] S. Wang and B. Xu, "Designing and implementation of a process control system simulation software," Research and Exploration in Laboratory, vol. 21, pp. 53-55, 2002.

[5] B. Robert N, Introduction to Control System Technology. Beijing: Pearon Educatio North Aisa and China Machine Press, 2006.

[6] Y. Jin, Process control. Beijing: Tsinghua university press, 2005.

\section{AUTHORS}

Chunguo Fei received the Ph.D. degree in Department of Automation from Shanghai Jiaotong University, Shanghai, China, in 2006. He is associate professor in Department of Automation, Civil Aviation University of China. (email: fchunguo@163.com)

Chunxin Li was born in Tianjin, China, in 1992. He received the B.Sc degree in electrical engineering and automation from Yangtze University, Jingzhou, China, in 2014, and he is currently pursuing the M.Sc degree in control engineering from Civil Aviation University Of China, Tianjin, China, (email:chunxin_li@126.com).

Submitted, 09 March 2015. Published as resubmitted by the authors on 09 April 2015. 